\title{
A Twin-head "V" High-wire Greenhouse Cucumber Production System for Reducing Crop Start-up Costs
}

\author{
Xiuming $\mathrm{Hao}^{1,3}$, Guang Wen ${ }^{1}$, Athanasios P. Papadopoulos ${ }^{1}$, \\ and Shalin Khosla ${ }^{2}$
}

AdDITIONAL INDEX wORDs. Cucumis sativus, raised-trough, training, growth, yield, grade

Summary. A high-wire system, in which the plant is trained into a single stem, is gaining popularity in year-round greenhouse cucumber (Cucumis sativus) production, especially with supplemental lighting, as it allows for uniform foliar and light distribution and higher yield and quality. However, this system requires much higher plant densities than the conventional umbrella system, resulting in increased crop start-up costs. A technique for raising twin-head transplants and a twin-head "V" high-wire cucumber system were developed to address this issue. The twin-head transplants were raised by topping the seedlings after the appearance of the fourth true leaf and then two strong lateral shoots were allowed to develop and be trained into a "V" system after planting. The twin-head system achieved similar plant growth and fruit yield as the conventional single-head system on two long English seedless cucumber cultivars (Bodega and Myrthos) and two breeding lines (2005A and 24-119) tested over 2 years. The twin-head system also improved the fruit grades in 'Bodega' by increasing the percentage of fruit in medium size while reducing the percentage of fruit in small size. Because the twin-head system achieved the same fruit yield as the conventional single-head system while using only half the number of transplants, we can conclude that the twin-head "V" high-wire system is a more cost-effective high-wire system for year-round greenhouse cucumber production.

G reenhouse vegetable production is embracing the rapidly increasing market shares in North America (Cook and Calvin, 2005). The industry, centered in Leamington, ON, Canada, has more than doubled in the past 10 years (Ontario Ministry of Agriculture and Food, 2005). Following heavy investments in modern capital-intensive production facilities, improved cultivation technologies are essential for producers to realize the anticipated high productivity potential of the improved growing conditions in the greenhouse.

This research was funded in part by the Ontario Greenhouse Vegetable Growers and the Matching Investment Initiative of Agriculture and Agri-Food Canada.

We thank Nick DiMenna, Jingming Zheng, and Pascal Brouwers for their technical support.

The mention of trade names in this manuscript does not imply product endorsement by the authors and their associated institutions.

${ }^{1}$ Greenhouse and Processing Crops Research Centre, Agriculture and Agri-Food Canada, 2585 County Road 20, Harrow, ON, Canada N0R IG0

${ }^{2}$ Ontario Ministry of Agriculture, Food and Rural Affairs, Greenhouse and Processing Crops Research Centre, 2585 County Road 20, Harrow, ON, Canada NOR IG0

${ }^{3}$ Corresponding author. E-mail: xiuming.hao@agr.gc.ca.
Greenhouse cucumbers (seedless long English type) traditionally are cultivated using an umbrella training system. With this system, young plants are trained to grow upward to an overhead wire hung at $\approx 2 \mathrm{~m}$ height; once these plants reach the wire, every plant is topped and two main laterals are trained to grow along the wire horizontally for $\approx 0.5 \mathrm{~m}$ and then hung down from the wire; the laterals are topped at $\approx 1 \mathrm{~m}$ below the wire, and the new laterals are continually allowed to grow in this way to form an "umbrella" canopy (Ontario Ministry of Agriculture and Food, 2005; Papadopoulos, 1994). Since the leaves are intensively distributed around the overhead wire, they prevent the penetration of light into the lower crop canopy. While the upper leaves above the wire may experience light saturation, the lower leaves are usually below light compensation point. Heavily shaded lower leaves do not contribute significantly to fruit production (Hovi et al., 2004), and the quality of the fruit inside the crop canopy also suffers due to poor fruit color. The umbrella system tends to have a large fluctuation in fruit production with poor fruit quality (Papadopoulos, 1994).

Cucumbers harvested from the upper canopy generally have longer shelf life than those from the lower canopy (Lin and Ehret, 1991). Improved light penetration into the canopy promotes chlorophyll formation and cucumber skin's chlorophyll content at harvest, which positively correlates with the shelf life (Lin and Jolliffe, 1996). Lighting or improved natural light penetration into the lower part of canopy increases cucumber fruit growth and improves the fruit quality (Adams et al., 2002; Aikman, 1989; Schapendonk and Brouver, 1984); such improved light penetration into the lower crop canopy may be achieved by improving the crop training system (Klieber and Lin, 1993).

In the high-wire training system, the plant is trained on a vertical string or wire with a clip system. Only the main stem (shoot) is allowed to grow and all the laterals/suckers are removed. Once the plant reaches the overhead support wire, the bottom leaves are removed and the plant is lowered. This training system allows much more uniform leaf distribution and better light penetration into the canopy, and thus promises more stable fruit production with high quality. To prevent the fruit from touching the ground, the high-wire system is preferably used in conjunction with the raised-trough system (Ontario

\begin{tabular}{llll}
\hline $\begin{array}{l}\text { Units } \\
\begin{array}{l}\text { To convert U.S. to SI, } \\
\text { multiply by }\end{array}\end{array}$ & U.S. unit & SI unit & $\begin{array}{l}\text { To convert SI to U.S., } \\
\text { multiply by }\end{array}$ \\
\hline 0.3048 & $\mathrm{ft}$ & $\mathrm{m}$ & 3.2808 \\
0.0929 & $\mathrm{ft}^{2}$ & $\mathrm{~m}^{2}$ & 10.7639 \\
0.0283 & $\mathrm{ft}^{3}$ & $\mathrm{~m}^{3}$ & 35.3147 \\
2.54 & inch $(\mathrm{es})_{\text {inch }(\mathrm{es})}$ & $\mathrm{cm}$ & 0.3937 \\
25.4 & $\mathrm{~mm}$ & 0.0394 \\
6.4516 & inch & $\mathrm{cm}^{2}$ & 0.1550 \\
4.8824 & $\mathrm{lb} / \mathrm{ft}^{2}$ & $\mathrm{~kg} \cdot \mathrm{m}^{-2}$ & 0.2048 \\
1.6093 & $\mathrm{mile}(\mathrm{s})$ & $\mathrm{km}$ & 0.6214 \\
28.3495 & $\mathrm{oz}$ & $\mathrm{g}$ & 0.0353 \\
$4.3942 \times 10^{6}$ & $\mathrm{oz} / \mathrm{inch}^{2}$ & $\mu \mathrm{\mu g} \cdot \mathrm{cm}^{-2}$ & $2.2757 \times 10^{-7}$ \\
1 & $\mathrm{ppm}$ & $\mu \mathrm{L}^{-1}$ & $\mathrm{l}$
\end{tabular}


Ministry of Agriculture and Food, 2005). The raised-trough system also facilitates nutrient solution recycling, air circulation in the lower crop canopy, and fruit harvesting. The high-wire system on raised-troughs is gaining popularity in commercial greenhouse cucumber production, especially for year-round production with supplemental lighting (Hendriks, 1992; Hovi et al., 2004). Because the system originally allowed for only one stem per plant, much higher plant densities [2.2 to 4 plants $/ \mathrm{m}^{2}$ (Hao et al., 2009)] were needed to achieve high yield, in comparison with the conventional umbrella system [ 1.4 to 1.8 plants $/ \mathrm{m}^{2}$ (Ontario Ministry of Agriculture and Food, 2005)]. This inadvertently has resulted in higher crop start-up costs. The cost of greenhouse seedless cucumber transplants is very high [Canadian dollar (C\$) 1.5/ transplant in the winter and C\$1.3/ transplant in the summer (L. Wilson, personal communication)]. Therefore, we conducted a research project to develop a twin-head "V" high-wire system on raised-troughs to reduce crop start-up costs. This article reports on the plant growth and fruit production performance of this twin-head "V" high-wire system, as compared with the conventional single-head high-wire cucumber system.

\section{Materials and methods}

The experiments were conducted in three identical greenhouse compartments $(7.5 \mathrm{~m}$ long $\times 7.2 \mathrm{~m}$ wide $\times 4 \mathrm{~m}$ gutter height; south-north orientation) over two growing seasons (May to Oct. 2005 and Mar. to Aug. 2006) at the Greenhouse and Processing Crops Research Center, Agriculture and Agri-Food Canada, Harrow, ON, Canada (lat. $42^{\circ} \mathrm{N}$ ). The cucumber plants in half of the area in each compartment were grown with twinhead "V" high-wire system, whereas the other half of each compartment was used for growing cucumber plants with the conventional single-head high-wire system (Fig. 1). Therefore, each greenhouse compartment provided a complete replication (block) of the two treatments (systems). Four long English cucumber cultivars or breeding lines ('Bodega', 2005A, and 24-119 grown in 2005; 'Myrthos' grown in 2006) were used in the experiments.

Several protocols for raising twinhead transplants were evaluated before conducting the greenhouse experiments. It was found that the best protocol to obtain maximum transplant growth and balanced growth of two laterals was to top the seedlings after the appearance of the fourth true leaf. To raise twin-head transplants, one seed was directly seeded in a rockwool block $\left(10 \times 10 \times 7.5 \mathrm{~cm} ;\right.$ Pargro ${ }^{\circledR}$, Orllia, ON, Canada) at $\approx 4$ weeks before the anticipated date for planting into the greenhouse. The transplants were topped at the first appearance of the fourth true leaf. All suckers/lateral shoots in the four nodes were allowed to develop. When the largest sucker/ lateral shoot reached $\approx 5-7 \mathrm{~cm}$ in length (Fig. 2), the transplants were ready for planting into the greenhouse; suckers that are too large $(>10 \mathrm{~cm})$ will make the transport of the transplants difficult. The twin-head transplants need to be seeded $3 \mathrm{~d}$ (in the summer) to $4 \mathrm{~d}$ (in the winter) earlier than the conventional single-head transplants to achieve the same transplant size at the time of planting into the greenhouse because of the delay in growth caused by the topping. The transplants were raised on benches and flood irrigated using a Harrow Fertigation Manager (Papadopoulos and Liburdi, 1989) according to the standard nutrient recommendations (Ontario Ministry of Agriculture and Food, 2005). The conventional single-head transplants were raised in the same way as the twin-head transplants except that the main shoot was not topped and all lateral suckers/shoots were removed.

On 5 May 2005 or on 13 Apr. 2006, the twin-head and single-head
Single-head system

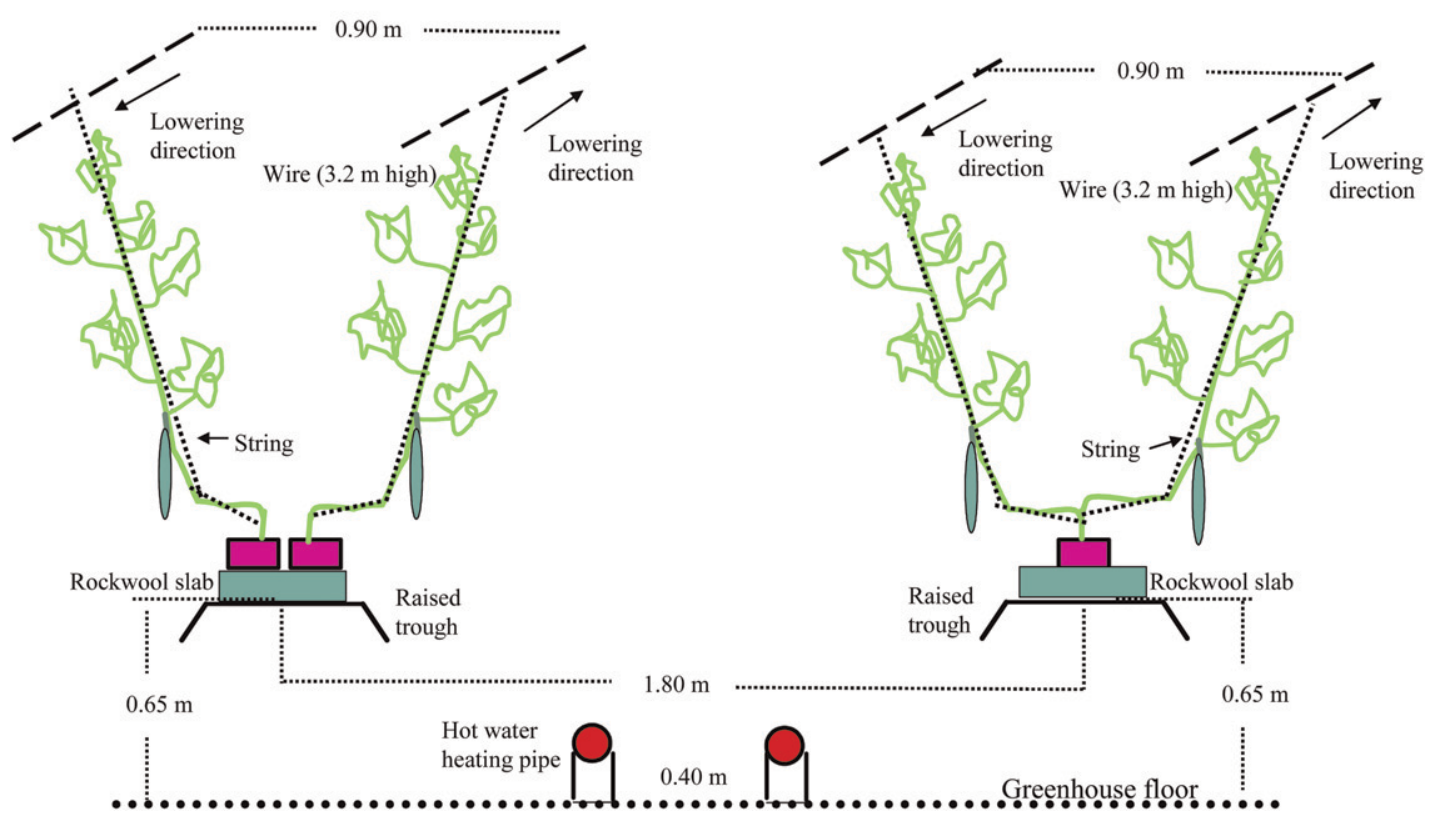

Fig. 1. Set-up of the conventional single-head high-wire and twin-head "V" high-wire cucumber production systems on the raised troughs. $1 \mathrm{~m}=3.2808 \mathrm{ft}$. 
transplants were planted onto the rockwool slabs $(50 \times 20 \times 10 \mathrm{~cm}$; Grodan ${ }^{\circledR}$, Milton, ON, Canada) laid on top of the raised troughs hung at $65 \mathrm{~cm}$ above the ground in the three greenhouse compartments (Fig. 1). Twenty-four slabs were used in each compartment, which were placed on four raised troughs, with each trough having six slabs. The two side troughs served as guard rows. Each of the twinhead and the conventional single-head system occupied a center row and an adjacent guard row. Four twin-head or eight single-head transplants were placed onto each rockwool slab in the center row, which had a plant density of 2 plants $/ \mathrm{m}^{2}$ for the twin-head or 4 plants $/ \mathrm{m}^{2}$ for the single-head system. In 2005, each cultivar or breeding line ('Bodega', 2005A, and 24-119) occupied two slabs in each row, and in 2006, 'Myrthos' occupied six slabs.

Four days after planting, the two weakest lateral shoots (usually the shoot from the first and fourth nodes) were removed from the transplants of the twin-head system, whereas the two remaining shoots were trained to grow upwards along the vertical strings in a "V" shape (Fig. 3). All subsequent

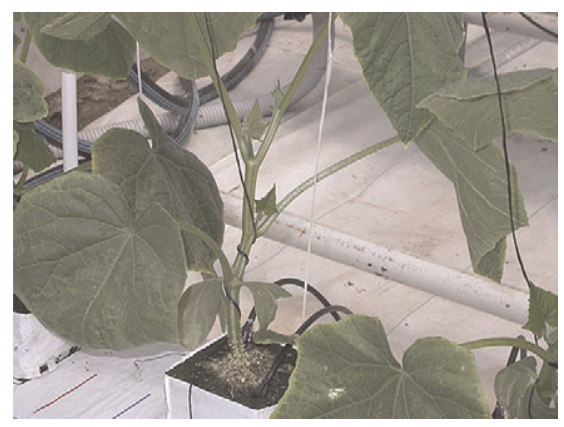

Fig. 2. Twin-head cucumber transplant just after planting onto the rockwool slab. The suckers in the second, third, and fourth node are clearly visible.

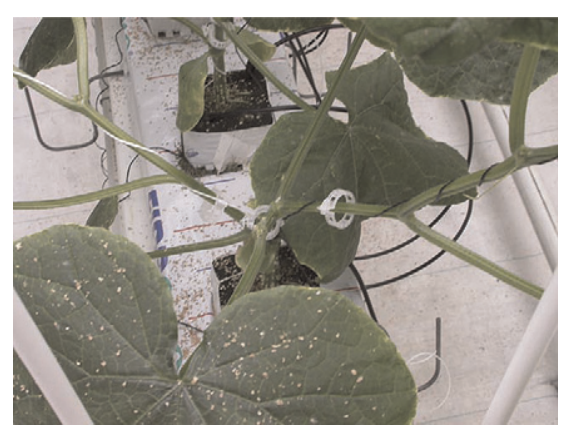

Fig. 3. Twin-head cucumber plant trained into a "V" system. suckers/lateral shoots from each of the two shoots (stems) were removed. For the conventional single-head system, only the main shoot (stem) was allowed to grow along the vertical string and all the suckers were removed. This method resulted in an equal stem/shoot density for the twin-head and the single-head systems (4 stems $\left./ \mathrm{m}^{2}\right)$. The stems/shoots were first lowered when they were $\approx 1 \mathrm{~m}$ in length while they were still flexible and then as required (one to two times per week, depending on plant growth) to keep them below the overhead wires (at $3.2 \mathrm{~m}$ high) (Fig. 1). All plants were drip-irrigated according to standard nutrient recommendations (Ontario Ministry of Agriculture and Food, 2005 ); to avoid nutrient imbalances in the rockwool slabs, $20 \%$ to $30 \%$ extra nutrient solution was applied. The greenhouse ventilation temperature and heating temperature were controlled by an Argus climate control computer according to blue-print recommendations by the Ontario Ministry of Agriculture and Food (2005). Greenhouse carbon dioxide $\left(\mathrm{CO}_{2}\right)$ was enriched to $1000 \mu \mathrm{L} \cdot \mathrm{L}^{-1}$ when the greenhouses were not ventilated or to $400 \mu \mathrm{L} \cdot \mathrm{L}^{-1}$ when they were ventilated, with a central supply of liquid $\mathrm{CO}_{2}$.

Fruit harvest AND GRADING. Fruit harvest was started on 2 June and completed on 14 Oct. in 2005, while it was started on 12 May and completed on 18 Aug. in 2006. Fruit was harvested two to three times per week and was graded according to the commercial grading standards (Ontario Ministry of Agriculture, Food and Rural Affairs, 2004). The Canada no. 1 fruit consists of the small, medium, large, and extra large fruit, each with a minimum diameter of $41 \mathrm{~mm}$, no visible defects, and a length of 280-317 mm (small), 317-368 mm (medium), 368-419 mm (large), and over 419 $\mathrm{mm}$ (extra large). Grade no. 2 fruit is a fruit with visible defects (such as large curviness) or less than $41 \mathrm{~mm}$ in diameter, but is still marketable.

Growth measurements. Plant growth parameters were measured three times in each year (6 July, 3 Aug., and 31 Aug. in 2005 and 10 May, 21 June, and 18 July in 2006). Four plants or stems from each cultivar under either the single or the twinhead system in each compartment were measured. The length, width, and chlorophyll readings (SPAD 502; Minota, Osaka, Japan) of the fifth and 10th fully expanded leaf were recorded. Leaf area and leaf chlorophyll content were calculated according to the empirical equations developed by Hao and Papadopoulos (1999).

Statistical analysis. Analysis of variance (ANOVA) was conducted with

Table 1. Analysis of variance on the growth parameters of long English cucumber (cultivar Bodega and breeding lines 2005A and 24-119 in 2005; cultivar Myrthos in 2006) grown with the single-head high-wire and twin-head "V" high-wire systems.

\begin{tabular}{|c|c|c|c|c|c|c|c|}
\hline \multirow[b]{2}{*}{ Date } & \multirow{2}{*}{\multicolumn{2}{|c|}{ Factor }} & \multirow[b]{2}{*}{$\begin{array}{l}\text { Plant ht } \\
(\mathrm{cm})^{\mathrm{z}}\end{array}$} & \multicolumn{2}{|c|}{5 th leaf } & \multicolumn{2}{|c|}{ 10th leaf } \\
\hline & & & & $\begin{array}{l}\text { Leaf } \\
\text { area } \\
\left(\mathrm{cm}^{2}\right)^{z}\end{array}$ & $\begin{array}{c}\text { Chlorophyll } \\
\text { content } \\
\left(\mu \mathrm{g} \cdot \mathrm{cm}^{-2}\right)^{\mathrm{z}}\end{array}$ & $\begin{array}{l}\text { Leaf } \\
\text { area } \\
\left(\mathrm{cm}^{2}\right) \\
\end{array}$ & $\begin{array}{c}\text { Chlorophyll } \\
\text { content } \\
\left(\mu \mathrm{g} \cdot \mathrm{cm}^{-2}\right)\end{array}$ \\
\hline \multirow[t]{9}{*}{2005} & 6 July & System $^{\mathrm{y}}$ & NS & * & NS & NS & * \\
\hline & & $\begin{array}{l}\text { Cultivar } \\
\text { or breeding } \\
\text { line }(\mathrm{C} / \mathrm{BL})\end{array}$ & NS & NS & NS & NS & NS \\
\hline & & System $\times \mathrm{C} / \mathrm{BL}$ & NS & NS & NS & NS & NS \\
\hline & 3 Aug. & System & NS & NS & NS & NS & NS \\
\hline & & $\mathrm{C} / \mathrm{BL}$ & NS & NS & NS & NS & NS \\
\hline & & System $\times \mathrm{C} / \mathrm{BL}$ & NS & NS & NS & NS & NS \\
\hline & 31 Aug. & System & NS & NS & NS & NS & NS \\
\hline & & $\mathrm{C} / \mathrm{BL}$ & NS & NS & NS & NS & * \\
\hline & & System $\times C / B L$ & NS & NS & NS & NS & NS \\
\hline \multirow[t]{3}{*}{2006} & 10 May & System & NS & NS & NS & * & NS \\
\hline & 21 June & System & NS & NS & NS & NS & NS \\
\hline & 18 July & System & NS & NS & NS & NS & NS \\
\hline
\end{tabular}

${ }^{\mathrm{z}} \mathrm{l} \mathrm{cm}=0.3937$ inch, $1 \mathrm{~cm}^{2}=0.1550$ inch $^{2}, 1 \mu \mathrm{g} \cdot \mathrm{cm}^{-2}=2.2757 \times 10^{-7} \mathrm{oz} /$ inch $^{2}$.

"Single-head high-wire system or twin-head "V" high-wire system.

Ns, * Nonsignificant or significant at $P \leq 0.05$, respectively. 
the general linear model procedure of SAS (version 9.0; SAS Institute, Cary, NC). Two-way (head system and cultivars) ANOVA on the 2005 data and one-way (head system only) ANOVA on the 2006 data, both with three replications (greenhouse), were performed. Separate ANOVA was conducted on plant growth parameters for each measurement date. When a main treatment (head systems or cultivars) effect was significant $(P \leq 0.05)$, a least significant difference $t$ test was used to separate the treatment means.

\section{Results}

Plant growth. Out of the five plant growth parameters (plant height, leaf area, and chlorophyll contents of the fifth and 10th fully expanded leaves) evaluated on three dates in
2005 , the head systems had significant effects only on the size of the fifth leaf and the chlorophyll content of the 10th leaf in the first measurement [on 6 July (Table 1)]; the size of the fifth leaf in 'Bodega' with the twinhead system was $\approx 14 \%$ smaller than that with the single-head system, whereas the chlorophyll content of the 10th leaf in 24-119 with twinhead system was $8 \%$ higher than that with the single-head system (Table 2 ). In 2006, of the five plant growth parameters evaluated on three dates, the head systems had significant effect only on the size of the 10th leaf in the first measurement (10 May, Table 1); the leaf area of the 10th leaf with the twin-head system was 16\% larger than that with single-head system (Table 3 ). Cultivars also had little effects on plant growth parameters in 2005 (Table 1). Of the five plant growth parameters evaluated on three dates in 2005 , the cultivars only affected the chlorophyll content of the 10th fully expanded leaf measured on 31 Aug. 2005 (Table 1); the chlorophyll content of the 10th leaf in 24-119 was 13\% lower than that in 2005A (Table 2). There was no interaction between the cultivars and the head systems on the plant growth parameters (Table 1).

Fruit YIELD AND GRADES. The head systems did not affect the total and marketable fruit yield (expressed as number; long English cucumbers are sold by the number in North American market), fruit weight, fruit size, and percentages of grade no. 1 and no. 2 fruits (Tables 4 and 5 ), but they did change the distribution of

Table 2. Growth parameters of long English cucumber (cultivar Bodega and breeding lines 2005A and 24-119) grown with the single-head high-wire and twin-head "V" high-wire systems in 2005.

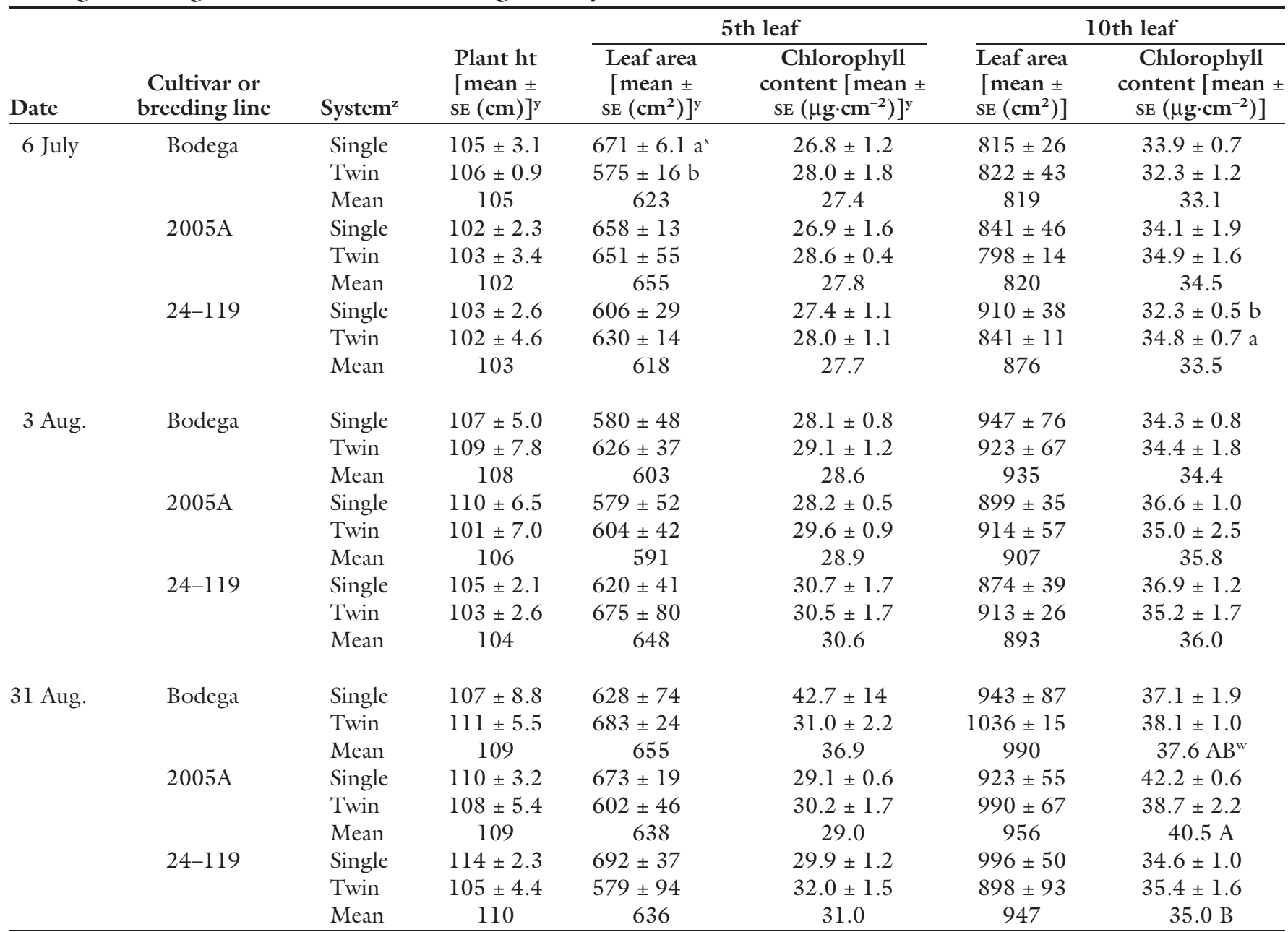

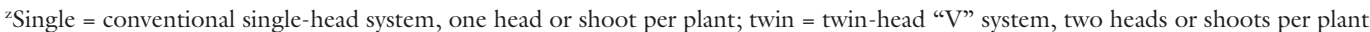

${ }^{y} 1 \mathrm{~cm}=0.3937$ inch, $1 \mathrm{~cm}^{2}=0.1550 \mathrm{inch}^{2}, 1 \mu \mathrm{g} \cdot \mathrm{cm}^{-2}=2.2757 \times 10^{-7} \mathrm{oz} / \mathrm{inch}^{2}$.

${ }^{x}$ Values followed by different letters $(\mathrm{a}$ and $\mathrm{b})$ in a column within the same cultivar or breeding line are significantly different $(P \leq 0.05)$ as determined by least significant difference (LSD) tests; there is no significant difference $(P>0.05)$ between the values when they are not followed by any letters.

${ }^{\text {w} C u l t i v a r ~ o r ~ b r e e d i n g ~ l i n e ~ m e a n s ~ f o l l o w e d ~ b y ~ d i f f e r e n t ~ l e t t e r s ~(A ~ a n d ~ B) ~ i n ~} 2005$ indicate a significant $(P \leq 0.05)$ difference as determined by LSD tests; there is no significant difference $(P>0.05)$ between the cultivar or breeding line means when they are not followed by any letters. 
Table 3. Growth parameters of long English cucumber (cultivar Myrthos) grown with the single-head high-wire and twin-head "V" high-wire systems in 2006.

\begin{tabular}{|c|c|c|c|c|c|c|}
\hline \multirow[b]{2}{*}{ Date } & \multirow[b]{2}{*}{ System $^{z}$} & \multirow[b]{2}{*}{$\begin{array}{l}\text { Plant ht } \\
{[\text { mean } \pm} \\
\mathrm{SE}(\mathrm{cm})]^{\mathrm{y}}\end{array}$} & \multicolumn{2}{|c|}{ 5th leaf } & \multicolumn{2}{|c|}{ 10th leaf } \\
\hline & & & $\begin{array}{c}\text { Leaf } \\
\text { area } \\
{[\text { mean } \pm} \\
\left.\operatorname{SE}\left(\mathrm{cm}^{2}\right)\right]^{\mathrm{y}}\end{array}$ & $\begin{array}{c}\text { Chlorophyll } \\
\text { content } \\
{[\text { mean } \pm \mathrm{SE}} \\
\left.\left(\mu \mathrm{g} \cdot \mathrm{cm}^{-2}\right)\right]^{\mathrm{y}}\end{array}$ & $\begin{array}{l}\text { Leaf area } \\
{[\text { mean } \pm} \\
\left.\operatorname{SE}\left(\mathrm{cm}^{2}\right)\right]\end{array}$ & $\begin{array}{c}\text { Chlorophyll } \\
\text { content } \\
{[\text { mean } \pm \mathrm{SE}} \\
\left.\left(\mu \mathrm{g} \cdot \mathrm{cm}^{-2}\right)\right]\end{array}$ \\
\hline \multirow[t]{2}{*}{10 May } & Single & $270 \pm 4.2$ & $551 \pm 41$ & $29.4 \pm 1.3$ & $1072 \pm 65 b^{x}$ & $31.5 \pm 0.4$ \\
\hline & Twin & $280 \pm 6.4$ & $681 \pm 82$ & 29.6 & $1248 \pm 71 \mathrm{a}$ & 31.6 \\
\hline \multirow[t]{2}{*}{21 June } & Single & $106 \pm 1.9$ & $471 \pm 27$ & $24.8 \pm 1.4$ & $957 \pm 71.2$ & 34.0 \\
\hline & Twin & $108 \pm 1.8$ & $517 \pm 31$ & $26.4 \pm 2.0$ & $933 \pm 69.8$ & $35.5 \pm 4.2$ \\
\hline \multirow[t]{2}{*}{18 July } & Single & $109 \pm 3.8$ & $471 \pm 20$ & $28.6 \pm 1.3$ & $686 \pm 54.2$ & $38.2 \pm 1.4$ \\
\hline & Twin & $109 \pm 2.8$ & $424 \pm 24$ & $29.2 \pm 1.9$ & $722 \pm 44.9$ & $38.4 \pm 1.3$ \\
\hline
\end{tabular}

${ }^{2}$ Single $=$ conventional single-head system, one head or shoot per plant; twin $=$ twin-head "V" system, two heads or shoots per plant.

${ }^{y} 1 \mathrm{~cm}=0.3937$ inch, $1 \mathrm{~cm}^{2}=0.1550 \mathrm{inch}^{2}, 1 \mu \mathrm{g} \cdot \mathrm{cm}^{-2}=2.2757 \times 10^{-7} \mathrm{oz} / \mathrm{inch}^{2}$.

'Values followed by different letters ( $\mathrm{a}$ and $\mathrm{b}$ ) in a column on the same date are significantly different $(P \leq 0.05)$ as determined by least significant difference tests; there is no significant difference $(P>0.05)$ between the values when they are not followed by any letters.

Table 4. Analysis of variance on fruit yield and grades of long English cucumber (cultivar Bodega and breeding lines 2005A and 24-119 in 2005; cultivar Myrthos in 2006) grown with the single-head high-wire and twin-head "V" high-wire systems.

\begin{tabular}{|c|c|c|c|c|c|}
\hline \multirow[b]{2}{*}{$\underline{\text { Yr }}$} & \multirow{2}{*}{\multicolumn{2}{|c|}{ Parameter }} & \multicolumn{3}{|c|}{ Factor } \\
\hline & & & \multirow{2}{*}{ System $^{\text {z }}$} & \multirow{2}{*}{$\begin{array}{c}\begin{array}{c}\text { Cultivar or } \\
\text { breeding } \\
\text { line }(\mathrm{C} / \mathrm{BL})\end{array} \\
*\end{array}$} & \multirow{2}{*}{$\begin{array}{c}\begin{array}{c}\text { System } \times \\
\text { C/BL }\end{array} \\
\text { Ns }\end{array}$} \\
\hline \multirow[t]{7}{*}{2005} & Total fruit & Number $\left(\text { fruit } / \mathrm{m}^{2}\right)^{\mathrm{y}}$ & & & \\
\hline & & Weight $\left(\mathrm{kg} \cdot \mathrm{m}^{-2}\right)^{\mathrm{y}}$ & NS & NS & NS \\
\hline & Marketable fruit & Number (fruit $/ \mathrm{m}^{2}$ ) & NS & * & NS \\
\hline & & Weight $\left(\mathrm{kg} \cdot \mathrm{m}^{-2}\right)$ & NS & NS & NS \\
\hline & & Size $(g / \text { fruit })^{y}$ & NS & * & NS \\
\hline & & Grade no.l fruit $(\%)^{x}$ & NS & * & NS \\
\hline & & Grade no. 2 fruit $(\%)^{x}$ & NS & * & NS \\
\hline \multirow[t]{7}{*}{2006} & Total fruit & Number (fruit $/ \mathrm{m}^{2}$ ) & NS & - & - \\
\hline & & Weight $\left(\mathrm{kg} \cdot \mathrm{m}^{-2}\right)$ & NS & - & - \\
\hline & Marketable fruit & Number (fruit $/ \mathrm{m}^{2}$ ) & NS & - & - \\
\hline & & Weight $\left(\mathrm{kg} \cdot \mathrm{m}^{-2}\right)$ & NS & - & - \\
\hline & & Size (g/fruit) & NS & - & - \\
\hline & & Grade no.1 fruit (\%) & NS & - & - \\
\hline & & Grade no. 2 fruit (\%) & NS & - & - \\
\hline
\end{tabular}

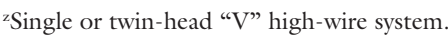

$\mathrm{y} l$ fruit $/ \mathrm{m}^{2}=0.0929$ fruit $/ \mathrm{ft}^{2}, \mathrm{l} \mathrm{kg} \cdot \mathrm{m}^{-2}=0.2048 \mathrm{lb} / \mathrm{ft}^{2}, \mathrm{lg}=0.0353 \mathrm{oz}$.

x Percentage of fruit number over marketable fruit number. Grade no. I fruit is fruit with no visible defects, a minimum diameter of $41 \mathrm{~mm}$ ( 1.61 inches), and a length more than $280 \mathrm{~mm}$ (11.02 inches); grade no. 2 fruit is fruit with visible defects (such as large curviness) or less than $41 \mathrm{~mm}$ in diameter, but is still marketable.

Ns, * Nonsignificant or significant at $P \leq 0.05$, respectively.

grade no.l fruit between the medium and small category in 2005 (Tables 6 and 7). The twin-head system produced a higher percentage of medium but lower percentage of small fruit than the single-head system in 'Bodega' (Table 7).

The three cultivars or breeding lines in 2005 produced similar total and marketable fruit weight (Tables 4 and 5), which indicated that they had similar biological yield potential. However, they had significant difference on fruit number, size, and fruit distribution across different fruit grades (Tables 4-7). Breeding line $2005 \mathrm{~A}$ produced the highest number of total and marketable fruit but with the smallest fruit size among the three cultivars or breeding lines (Table 5).
'Bodega' produced the least number of fruit but with the largest fruit size. 'Bodega' also had the highest percentage of no. 1 fruit (top fruit grade) and the lowest percentage of no. 2 fruit (inferior fruit). Because of its larger fruit size, it also had the lowest percentage of small fruit and the highest percentage of large and medium fruits (Table 7). Breeding line 2005A had the smallest fruit size and higher percentage of small fruit, and hence, had the worst fruit grades among the three cultivars/breeding lines in 2005 .

\section{Discussion}

One of the key considerations for a successful intensive crop production is to maximize outputs while minimizing inputs. The high-wire system has the potential for stable and high production of greenhouse cucumbers but requires high number of transplants, resulting in higher crop startup costs. The cost for long English cucumber transplants is high [C $\$ 1.5 /$ transplant in the winter and C\$1.3/ transplant in the summer (L. Wilson, personal communication)]. To reduce the crop start-up costs, we developed a twin-head "V" high-wire cucumber production system. This study was conducted to compare the crop performance of greenhouse cucumbers grown with the twin-head system and the conventional single-head highwire system.

In the 2 years of experiments with four cultivars/breeding lines, the plant growth and fruit yield of the twin-head system were similar to those of the conventional single-head system except for some minor difference on a few growth parameters in the early growth stage after planting (Tables l$5)$. The smaller fifth leaf in 'Bodega' (2005) and the larger 10th leaf in 'Myrthos' (2006) with twin-head system in the first measurement (Tables 2 and 3 ) might be due to the difference in the growth habits between the cultivars to generate suckers/laterals. There was little difference in plant growth between the two systems. The twin-head system had a higher percentage of medium fruit but a lower percentage of small fruit than did the single-head system in 'Bodega' (Table 7). In case of long English cucumbers, the large- and medium-sized cucumbers are sold at much higher price than the small-sized cucumbers. Therefore, the twin-head system can achieve 
Table 5. Fruit yield and grades of long English cucumber (cultivar Bodega and breeding lines 2005A and 24-119 in 2005; cultivar Myrthos in 2006) grown with the single-head high-wire and twin-head "V" high-wire systems.

\begin{tabular}{|c|c|c|c|c|c|c|c|c|c|}
\hline \multirow[b]{2}{*}{ Yr } & \multirow[b]{2}{*}{$\begin{array}{c}\text { Cultivar or } \\
\text { breeding } \\
\text { line }\end{array}$} & \multirow[b]{2}{*}{ System $^{\mathrm{z}}$} & \multicolumn{2}{|c|}{ Total fruit } & \multicolumn{5}{|c|}{ Marketable fruit } \\
\hline & & & $\begin{array}{c}\text { Number } \\
{[\text { mean } \pm \text { SE }} \\
\left.\left(\text { fruit } / \mathrm{m}^{2}\right)\right]^{\mathrm{y}}\end{array}$ & $\begin{array}{l}\text { Wt }[\text { mean } \pm \\
\left.\text { SE }\left(\mathrm{kg} \cdot \mathrm{m}^{-2}\right)\right]^{\mathrm{y}}\end{array}$ & $\begin{array}{c}\text { Number } \\
{[\text { mean } \pm \text { SE }} \\
\left.\left(\text { fruit } / \mathrm{m}^{2}\right)\right]\end{array}$ & $\begin{array}{l}\text { Wt }[\text { mean } \pm \\
\left.\mathrm{SE}\left(\mathrm{kg} \cdot \mathrm{m}^{-2}\right)\right]\end{array}$ & $\begin{array}{c}\text { Size } \\
{[\text { mean } \pm \text { SE }} \\
(\mathrm{g} / \text { fruit })]^{y}\end{array}$ & $\begin{array}{l}\text { Grade no.l } \\
\text { fruit [mean } \\
\pm \operatorname{SE}(\%)]^{\mathrm{x}}\end{array}$ & $\begin{array}{l}\text { Grade no. } 2 \\
\text { fruit [mean } \\
\pm S E(\%)]^{x} \\
\end{array}$ \\
\hline \multirow{6}{*}{2005} & & Twin & $102 \pm 6.0$ & $34.7 \pm 2.1$ & $94.2 \pm 5.2$ & $33.5 \pm 2.1$ & $356 \pm 17$ & $88.1 \pm 2.4$ & $11.9 \pm 2.4$ \\
\hline & & Mean & $102 \mathrm{~B}^{\mathrm{w}}$ & 34.1 & $92.7 \mathrm{~B}$ & 32.7 & $353 \mathrm{~A}$ & $86.8 \mathrm{~A}$ & $13.2 \mathrm{~B}$ \\
\hline & & Mean & $114 \mathrm{~A}$ & 34.4 & $103.6 \mathrm{~A}$ & 32.8 & 317 B & $80.1 \mathrm{~B}$ & $19.9 \mathrm{~A}$ \\
\hline & $24-119$ & Single & $111 \pm 3.0$ & $35.9 \pm 1.5$ & $97.7 \pm 4.0$ & $33.7 \pm 1.7$ & $344 \pm 3.9$ & $79.5 \pm 1.6$ & $20.5 \pm 1.6$ \\
\hline & & Twin & $108 \pm 1.1$ & $35.5 \pm 0.5$ & $99.2 \pm 1.9$ & $33.7 \pm 0.8$ & $340 \pm 1.9$ & $82.3 \pm 1.4$ & $17.6 \pm 1.4$ \\
\hline & & Mean & $109 \mathrm{AB}$ & 35.7 & $98.5 \mathrm{AB}$ & 33.7 & $342 \mathrm{~A}$ & 80.9 B & $19.1 \mathrm{~A}$ \\
\hline 2006 & Myrthos & Single & $107 \pm 2.0$ & $34.4 \pm 0.1$ & $99.3 \pm 7.3$ & $32.5 \pm 0.6$ & $329 \pm 4.0$ & $91.9 \pm 0.2$ & $8.1 \pm 0.2$ \\
\hline
\end{tabular}

${ }^{2}$ Single = conventional single-head system, one head or shoot per plant; twin = twin-head "V" system, two heads or shoots per plant.

$\mathrm{y}$ l fruit $/ \mathrm{m}^{2}=0.0929 \mathrm{fruit} / \mathrm{ft}^{2}, \mathrm{l} \mathrm{kg} \cdot \mathrm{m}^{-2}=0.2048 \mathrm{lb} / \mathrm{ft}^{2}, \mathrm{lg}=0.0353 \mathrm{oz}$.

xercentage of fruit number over marketable fruit number. Grade no. 1 fruit is fruit with no visible defects, a minimum diameter of 41 mm ( 1.61 inches), and a length more than $280 \mathrm{~mm}$ (11.02 inches); grade no. 2 fruit is fruit with visible defects (such as large curviness) or less than $41 \mathrm{~mm}$ in diameter, but is still marketable.

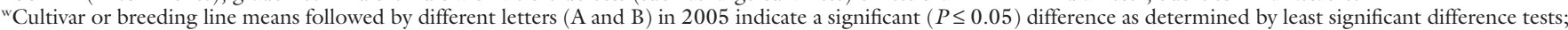
there is no significant difference $(P>0.05)$ between cultivar means when they are not followed by any letters.

Table 6. Analysis of variance on distribution of fruit in grade no. 1 for long English cucumber (cultivar Bodega and breeding lines 2005A and 24-119 in 2005; cultivar Myrthos in 2006) grown with the single-head high-wire and twin-head "V" high-wire systems.

\begin{tabular}{|c|c|c|c|c|c|}
\hline \multirow[b]{2}{*}{ Yr } & \multirow{2}{*}{\multicolumn{2}{|c|}{ Parameter }} & \multicolumn{3}{|c|}{ Factor } \\
\hline & & & \multirow{2}{*}{$\frac{\text { System }^{\text {z }}}{\text { NS }}$} & \multirow{2}{*}{$\begin{array}{c}\begin{array}{c}\text { Cultivar or } \\
\text { breeding line } \\
\text { (C/BL) }\end{array} \\
\text { NS }\end{array}$} & \multirow{2}{*}{$\begin{array}{c}\begin{array}{c}\text { System } \times \\
\mathrm{C} / \mathrm{BL}\end{array} \\
\mathrm{NS}\end{array}$} \\
\hline \multirow[t]{4}{*}{2005} & Grade no. 1 fruit & Extra large & & & \\
\hline & distribution $(\%)^{\mathrm{y}}$ & Large & NS & * & NS \\
\hline & & Medium & * & * & NS \\
\hline & & Small & * & * & NS \\
\hline \multirow[t]{4}{*}{2006} & Grade no. 1 fruit & Extra large & NS & - & - \\
\hline & distribution (\%) & Large & NS & - & - \\
\hline & & Medium & NS & - & - \\
\hline & & Small & NS & - & - \\
\hline
\end{tabular}

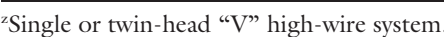

yercentage of fruit number over total grade no. 1 fruit number; grade no. 1 fruit consists of the small, medium, large, and extra large fruit, each with a minimum diameter of $41 \mathrm{~mm}$ ( 1.61 inches $)$, no visible defects, and a length of 280-317, 317-368, 368-419, and >419 mm (11.02-12.48, 12.48-14.49, 14.49-16.50, and >16.50 inches), respectively, for small, medium, large, and extra large fruit.

NS, * Nonsignificant or significant at $P \leq 0.05$, respectively.

better fruit grade than the conventional single-head system in some cultivars, such as Bodega.

It was observed during our greenhouse experiments that the twin-head transplants were less vulnerable to stem breakage during the initial plantlowering operation because their two laterals leaned to the side (at $\approx 30^{\circ}$ to $60^{\circ}$ angle to the direction of plant lowering) instead of being vertical (perpendicular to the direction of plant lowering) as were the case of the single-head transplants. As a result, fewer plant stems broke in the twin-head system than in the conventional single-head system. By the end of the greenhouse experiment in $2005,18.7 \%$ of original stems were broken in the conventional single-head system, whereas $11.3 \%$ (7.4\% less than the single-head) of original stems were broken in the twin-head system. These broken plants were eliminated from the greenhouse trials and their yield was not used in our yield calculation (fruit yield in each plot was first divided by plot stem number before any data analysis to remove the influence of stem breakage) because the incidence of stem damage is also strongly depended on the skill of the worker performing the operation. In our greenhouse experiments, the nonbroken plants with the twin-head system achieved the same yield as did the singlehead system. With more breakage in the conventional single-head system, the twin-head system could achieve higher fruit yield per unit of growing area than the single-head system in commercial production, depending on the skill of greenhouse workers on lowering the plants.

The set-up of the twin-head and the conventional single-head highwire system is identical except that the two transplants in the single-head system are replaced with one twin-head transplant (Fig. 1). Therefore, the input costs of twin-head "V" high-wire production system are the same as the conventional single-head high-wire system except for the transplant cost. The cost of single-head long English (seedless) cucumber transplant is about C\$1.5 in winter and C\$1.3 in summer (L. Wilson, personal communication); the difference in the costs between winter and summer is due to the difference in the duration for raising cucumber transplants ( 4 to 5 weeks 
in the winter vs. 2 to 3 weeks in the summer) and no heating cost in summer. The material cost and transportation cost for single-head and twin-head transplants are the same (Table 8 ). The only additional costs with the twinhead transplants are the labor costs for transplant topping and the costs for $3 \mathrm{~d}$

Table 7. Distribution of fruit in grade no. 1 for long English cucumber (cultivar Bodega and breeding lines 2005A and 24-119 in 2005; cultivar Myrthos in 2006) grown with the single-head high-wire and twin-head "V" high-wire systems.

\begin{tabular}{lcccccc}
\hline & & & \multicolumn{4}{c}{ Fruit distribution [mean \pm SE (\%) $]^{\mathrm{y}}$} \\
\cline { 3 - 6 } Yr & $\begin{array}{c}\text { Cultivar or } \\
\text { breeding line }\end{array}$ & System $^{\mathrm{z}}$ & $\begin{array}{c}\text { Extra } \\
\text { large }\end{array}$ & Large & Medium & Small \\
\hline 2005 & Bodega & Single & 0.1 & $10.8 \pm 1.2$ & $48.0 \pm 3.2 \mathrm{~b}^{\mathrm{x}}$ & $41.1 \pm 4.3 \mathrm{a}$ \\
& & Twin & 0.2 & $13.9 \pm 5.9$ & $58.9 \pm 0.1 \mathrm{a}$ & $27.0 \pm 6.2 \mathrm{~b}$ \\
& & Mean & 0.1 & $12.3 \mathrm{~A}^{\mathrm{w}}$ & $53.5 \mathrm{~A}$ & $34.1 \mathrm{C}$ \\
& \multirow{2}{*}{$2005 \mathrm{~A}$} & Single & 0 & $2.2 \pm 0.3$ & $32.8 \pm 2.8$ & $65.0 \pm 2.8$ \\
& & Twin & 0.1 & $1.6 \pm 0.7$ & $32.2 \pm 2.4$ & $66.1 \pm 1.7$ \\
& & Mean & 0.1 & $1.9 \mathrm{~B}$ & $32.5 \mathrm{C}$ & $65.6 \mathrm{~A}$ \\
& \multirow{2}{*}{$24-119$} & Single & 0 & $8.2 \pm 1.4$ & $48.5 \pm 1.5$ & $43.3 \pm 2.7$ \\
& & Twin & 0.1 & $7.9 \pm 2.0$ & $46.6 \pm 2.0$ & $45.4 \pm 1.3$ \\
& & Mean & 0 & $8.1 \mathrm{~A}$ & $47.5 \mathrm{~B}$ & $44.4 \mathrm{~B}$ \\
& & & & & \\
& \multirow{3}{*}{ Myrthos } & Single & 0.3 & $18.8 \pm 1.1$ & $55.3 \pm 1.1$ & $25.6 \pm 1.5$ \\
& & Twin & 0.4 & $21.2 \pm 1.2$ & $54.5 \pm 1.5$ & $23.9 \pm 0.6$ \\
& & Mean & 0.3 & 20 & 54.9 & 24.8 \\
\hline
\end{tabular}

${ }^{2}$ Single $=$ conventional single-head system, one head or shoot per plant; twin = twin-head "V" system, two heads or shoots per plant.

yercentage of fruit number over total grade no. 1 fruit number; grade no. I fruit consists of the small, medium, large, and extra large fruit, each with a minimum diameter of $41 \mathrm{~mm}$ ( 1.61 inches $)$, no visible defects, and a length of $280-317,317-368,368-419$, and $>419 \mathrm{~mm}$ (11.02-12.48, 12.48-14.49, 14.49-16.50, and $>16.50$ inches), respectively, for small, medium, large, and extra large fruit.

Values followed by different letters ( $\mathrm{a}$ and $\mathrm{b}$ ) in a column within the same cultivar or breeding line are significantly different $(P \leq 0.05)$ as determined by least significant difference (LSD) tests; there is no significant difference $(P>$ 0.05 ) between the values when they are not followed by any letters.

"Cultivar or breeding line means followed by different letters (A and B) in 2005 indicate a significant $(P \leq 0.05)$ cultivar difference as determined by LSD tests; there is no significant difference $(P>0.05)$ between the cultivar or breeding line means when they are not followed by any letters.

(in the summer) to $4 \mathrm{~d}$ (in the winter) of more growing time in the transplant greenhouse, which actually is a minor cost (about C\$0.05/transplant in the winter and C\$0.04/transplant in the summer) in comparison with the material costs (C\$0.73-C\$0.83/transplant: C\$0.5-0.6/seed, C\$0.18/rockwool block, C\$0.05/transplant for small seed plug and seed-covering material, such as vermiculite). When raising the transplants for our experiments, one worker topped 200 transplants in 15 $\min (\mathrm{C} \$ 15 / \mathrm{h} \times 0.25 \mathrm{~h} / 200$ transplants $=\mathrm{C} \$ 0.02 /$ transplant $)$. The 3 to $4 \mathrm{~d}$ of additional transplant growing costs about $\mathrm{C} \$ 0.02$ to $\mathrm{C} \$ 0.03$ per transplant (Table 8 ). Therefore, the input costs for each twin-head transplant are only $\approx 3 \%$ higher than those for the single-head transplant. Since the twin-head system used only half the number of transplants of the conventional single-head system, its transplant cost was reduced by almost half.

In conclusion, the twin-head "V" high-wire cucumber system can achieve the same fruit yield as the conventional single-head system and can also achieve better fruit grades in some cultivars, such as Bodega, while it reduces the transplant cost by almost half. Therefore, the twin-head "V" high-wire cucumber system is a more cost-effective

Table 8. Comparison of the cost components in Canadian dollars (C\$) for raising single-head and twin-head transplants. ${ }^{\mathrm{z}}$

\begin{tabular}{|c|c|c|c|c|}
\hline \multirow[b]{2}{*}{ Item } & \multicolumn{2}{|c|}{ Winter } & \multicolumn{2}{|c|}{ Summer } \\
\hline & $\begin{array}{c}\text { Single-head } \\
\text { (C\$/transplant) }\end{array}$ & $\begin{array}{c}\text { Twin-head } \\
\text { (C\$/transplant) }\end{array}$ & $\begin{array}{c}\text { Single-head } \\
\text { (C\$ / transplant) }\end{array}$ & $\begin{array}{c}\text { Twin-head } \\
\text { (C\$/transplant) }\end{array}$ \\
\hline Seed & $0.50-0.60$ & Same & $0.50-0.60$ & Same \\
\hline Rockwool block & 0.18 & Same & 0.18 & Same \\
\hline Seed plugs and cover material & 0.05 & Same & 0.05 & Same \\
\hline $\begin{array}{l}\text { Growing costs (water, fertilizers, } \\
\text { biological controls, carbon } \\
\text { dioxide, etc. })^{\mathrm{y}}\end{array}$ & 0.03 & $+0.01^{x}$ & 0.03 & +0.01 \\
\hline Heating $^{\mathrm{w}}$ & 0.09 & +0.01 & 0 & same \\
\hline Labor $^{v}$ & 0.12 & +0.02 & 0.08 & +0.02 \\
\hline $\begin{array}{l}\text { Greenhouse (interests on capital, } \\
\text { depreciation, and insurance) }\end{array}$ & $\begin{array}{l}0.06 \text { to } 0.11 \\
\quad(\text { old to new })^{\mathrm{u}}\end{array}$ & +0.01 & $\begin{array}{l}0.04 \text { to } 0.07 \\
\quad(\text { old to new })\end{array}$ & +0.01 \\
\hline Transportation $^{\mathrm{t}}$ & 0.05 & Same & 0.05 & Same \\
\hline Profits for transplant company & Unknown & Same & Unknown & Same \\
\hline
\end{tabular}

${ }^{2}$ Costs are calculated based on 30 transplants $/ \mathrm{m}^{2}\left(2.8\right.$ transplants $\left./ \mathrm{ft}^{2}\right)$ at the transplant greenhouse (Ontario Ministry of Agriculture and Food, 2005$) ; 30$ and $18 \mathrm{~d}$ are used for raising single-head cucumber transplants in the winter and summer, respectively; 34 and $21 \mathrm{~d}$ are used for raising twin-head cucumber transplants in the winter and summer, respectively.

${ }^{y}$ Estimation based on the data collected at the Greenhouse and Processing Crops Research Center, Agriculture and Agri-Food Canada, Harrow, ON, Canada, and confirmed by an anonymous source in commercial transplant production.

${ }^{\mathrm{x}}$ Number is rounded-up to C $\$ 0.01$.

${ }^{w}$ Calculation based on the coldest mo. in southwestern Ontario $\left[0.74 \mathrm{~m}^{3}\left(26.1 \mathrm{ft}^{3}\right)\right.$ natural gas per square foot per $30 \mathrm{~d}(\mathrm{Hao}$ et al., 2005$) ; \mathrm{C} \$ 0.33 / \mathrm{m}^{3}\left(\mathrm{C} \$ 0.934 / 100 \mathrm{ft}^{3}\right)$ natural gas $]$ and confirmed by an anonymous source in commercial transplant production.

vobtained from an anonymous source in commercial transplant production.

"Old to new: old to new greenhouse

'Within $50 \mathrm{~km}$ (31.1 miles), obtained from an anonymous source in commercial transplant production. 
system than the conventional singlehead high-wire system.

\section{Literature cited}

Adams, S.R., G.C. Woodward, and V.M. Valdés. 2002. The effect of leaf removal and of modifying temperature set points with solar radiation on tomato yields. J. Hort. Sci. Biotechnol. 77:733-738.

Aikman, D.P. 1989. Potential increase in photosynthetic efficiency from the redistribution of solar radiation in a crop. J. Expt. Bot. 40:855-864.

Cook, R. and L. Calvin. 2005. Greenhouse tomatoes change the dynamics of the North American fresh tomato industry. U.S. Dept. Agr., Econ. Res. Serv., Econ. Res. Rpt. ERR2. 2 Aug. 2010. <http:// www.ers.usda.gov/publications/ERR2>.

Hao, X., T. Jewett, and S. Khosla. 2005. Microclimate and energy consumption in commercial, hot-water and steam heated greenhouses for tomato production. Acta Hort. 691:171-178.

Hao, X. and A.P. Papadopoulos. 1999. Effects of supplemental lighting and cover materials on growth, photosynthesis, biomass partitioning, early yield and quality of greenhouse cucumber. Sci. Hort. 80: $1-18$.

Hao, X., A.P. Papadopoulos, and S. Khosla. 2009. Lighting in high-wire cucumber production on raised-troughs: interactions with other growth factors. 6th Intl. Symp. on Light in Hort. 15-19 Nov. 2009, Tsukuba, Japan. p. 70 (Abstr.).

Hendriks, J. 1992. Supplemental lighting for greenhouses. Acta Hort. 312:65-76.

Hovi, T., J. Näkkilä, and R. Tahvonen. 2004. Interlighting improves production of year-round cucumber. Sci. Hort. 102: 283-294.

Klieber, A. and W.C. Lin. 1993. Training systems affect canopy light exposure and shelf life of long English cucumber. J. Amer. Soc. Hort. Sci. 118:786-790.

Lin, W.C. and D.L. Ehret. 1991. Nutrient concentration and fruit thinning affect shelf life of long English cucumber. HortScience 26:1299-1300.

Lin, W.C. and P.A. Jolliffe. 1996. Light intensity and spectral quality affect fruit growth and shelf life of greenhousegrown long English cucumber. J. Amer. Soc. Hort. Sci. 121:1168-1173.

Ontario Ministry of Agriculture, Food and Rural Affairs. 2004. Greenhouse cucumber grading and packing manual. Ontario Ministry Agr., Food Rural Affairs, Food Safety and Environ. Div. Regulation $378 / 90$.

Ontario Ministry of Agriculture and Food. 2005. Growing greenhouse vegetables. Ontario Ministry Agr. Food Publ. 371.

Papadopoulos, A.P. 1994. Growing greenhouse seedless cucumbers in soil and in soilless media. Agr. Agri-Food Canada Publ. 1902/E.

Papadopoulos, A.P. and N. Liburdi. 1989. The Harrow Fertigation Manager ${ }^{\circledR}$, a computerized multifertilizer injector. Acta Hort. 260:255-266.

Schapendonk, A.H.C.M., and P. Brouver. 1984. Fruit growth of cucumber in relation to assimilate supply and sink activity. Sci. Hort. 23:21-23. 